\title{
Skin Transplantation
}

National Cancer Institute

\section{Source}

National Cancer Institute. Skin Transplantation. NCI Thesaurus. Code C15325.

The grafting of skin from one location to another in an attempt to replace a segment that is lost or damaged beyond repair. 